\title{
Studies on the Chemistry of Lichens
}

\section{Separation of Depside Components by Paper Chromatography}

\author{
CARLAXEL WACHTMEISTER
}

Organisk-kemiska Institutionen, Kungl. Tekniska Högskolan, Stockholm, Sweden

$I^{t}$

t has long been known that lichens contain a large variety of acidic conLtituents, generally termed "lichen acids", the structures of many of which have been elucidated. (For recent reviews see refs. 1 and 2.) The lichen acids may be divided into a number of groups, one of which comprises substances derived from orsellinic acid (I) and its homologues in various states of oxidation. The acids may occur (a) as simple depsides, (b) as depsidones which contain a diphenyl ether structure and are probably formed by a dehydrogenation process, or (c) as more condensed systems, obviously formed by a dehydrogenative coupling of monocyclic acids, of which the heterocyclic diphenyl derivative didymic acid ${ }^{3}$ is an example.

Several attempts have been made to base a botanical classification of the lichens on the occurrence of different types of lichen acids, and Asahina has developed micro-chemical methods which have proved of value 4,5 for this type of work. However these techniques which involve the use of a polarising microscope have not yet been widely used by botanists, and it appeared that an alternative method of identifying the lichen acids in small amounts of material would be desirable. This communication describes paper chromatographic methods which have been developed for the separation and characterisation of ten $(\mathrm{I}-\mathrm{X})$ of the 25 phenolic carboxylic acids known to be components of depsides.

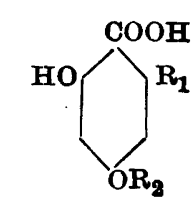

I $\mathrm{R}_{1}=\mathrm{CH}_{3}, \mathrm{R}_{2}=\mathrm{H}$

II $\quad \mathbf{R}_{1}=\mathbf{R}_{2}=\mathrm{CH}_{3}$

III $\mathrm{R}_{1}=n-\mathrm{C}_{3} \mathrm{H}_{7}, \mathrm{R}_{2}=\mathrm{H}$

IV $\mathrm{R}_{1}=n-\mathrm{C}_{3} \mathrm{H}_{7}, \mathrm{R}_{2}=\mathrm{CH}_{3}$

V $\quad \mathbf{R}_{1}=n-\mathrm{C}_{7} \mathrm{H}_{15}, \mathrm{R}_{2}=\mathrm{H}$

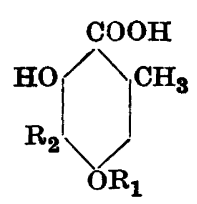

VI $\mathrm{R}_{1}=\mathrm{H}, \mathrm{R}_{2}=\mathrm{CH}_{3}$

VII $R_{1}=R_{2}=\mathrm{CH}_{3}$

VIII $\mathrm{R}_{1}=\mathrm{H}, \mathrm{R}_{2}=\mathrm{CHO}$

IX $\mathrm{R}_{1}=\mathrm{CH}_{3}, \mathrm{R}_{2}=\mathrm{CHO}$

$\mathrm{X} \quad \mathrm{R}_{1}=\mathrm{CH}_{3}, \mathrm{R}_{2}=\mathrm{COOH}$<smiles>[R]OCC(C)CO</smiles>

XI $\quad \mathrm{R}=\mathrm{CH}_{3}$

XII $\mathrm{R}=\mathrm{CHO}$ 
In the solvent systems generally used for acids, e.g. benzene - acetic acid - water ${ }^{6}$, the substances above often have $R_{F}$ values which are too high to give satisfactory separations. However, the method of Goodall and Levi 7, 8 , using buffer-impregnated paper, proved to be very useful, and by suitable choice of $\mathrm{pH}$ and solvents the degree of separation could be varied within wide limits. Trailing of the spots, often a disturbing factor in the case of acids, was greatly reduced.

The positions of the spots may be determined in several ways, the simplest being by examination of the chromatograms in ultra-violet light. The anions of all the phenolic carboxylic acids investigated, except those containing free aldehyde groupings, show a bluish-white fluorescence - the free acids on the other hand exhibit only a very faint fluorescence ${ }^{c f .}{ }^{9}$. Some of the acids related to atranol (XII) give a yellowish or green fluorescence on paper buffered at $\mathrm{pH}>8$ and this behaviour appears to be characteristic for some $o$-hydroxyaldehydes $e . g$. salicylaldehyde and $o$-vanillin although atranol itself does not fluoresce.

Many of the phenolic acids may be detected by spraying the chromatograms with a solution of bis-diazotised benzidine ${ }^{10}$ and the colours produced with this reagent give some indication of the structure of the compounds involved. Ammoniacal silver nitrate solution ${ }^{9}$ is reduced by 2,4-dihydroxy acids on heating at $80-100^{\circ}$ for a short time; acids having only one free hydroxyl group do not react. $p$-Phenylene diamine ${ }^{4}$ gives intense yellow spots with all the acids derived from atranol - a reaction which appears to be given by all $o$ - and $p$-hydroxy aldehydes. Finally, the same acids have a faint yellow colour when run on paper buffered to $\mathrm{pH}>7$ and this may be of diagnostic value, but the colour is often too faint to be observed.

The colour reactions given by the various acids are summarized in Table 1.

Some examples of the choice of conditions for separating phenolic carboxylic acids are given in Table 2. With the solvent system $n$-butanol - water, greatly improved separations may be achieved by increasing the $\mathrm{pH}$ of the phosphate buffer used for impregnating the strips. The most lipophilic acids move at nearly identical speed even at $\mathrm{pH} 11.7$, but butanol - benzene water $(1: 1: 1)$, at the same $\mathrm{pH}$, gives a god separation, although the hydrophilic acids then move very slowly. In this case a lower $\mathrm{pH}$ gives better results. On unbuffered paper benzene - water was found to give some separation of the lipophilic acids but extensive trailing was observed.

The use of papers buffered to high $\mathrm{pH}$ values causes partial oxidative destruction of the most sensitive acids (I, VI and VIII), yielding products with very low $R_{F}$ values. In this respect $\beta$-orcinol-carboxylic acid (VI) is interesting since a spot of this compound on paper buffered to $\mathrm{pH} 11.7$ after one day in a 
Table 1. Colour reactions.

\begin{tabular}{|c|c|c|c|c|}
\hline \multirow[b]{2}{*}{ Phenolic carboxylic acids } & \multirow{2}{*}{$\begin{array}{c}\text { Fluorescence } \\
\text { in ultra-violet }\end{array}$} & \multicolumn{3}{|c|}{ Colour with } \\
\hline & & $\begin{array}{c}\text { Benzidine } \\
\text { reagent }\end{array}$ & $\begin{array}{c}p \text {-Phenylene- } \\
\text { diamine }\end{array}$ & $\mathrm{AgNO}_{3}-\mathrm{NH}_{3}$ \\
\hline $\begin{array}{l}\text { Orsellinic acid (I) } \\
\text { Everninic acid (II) } \\
\text { Divaric acid (III) } \\
\text { Divaricatinic acid (IV) } \\
\text { Sphaerophorol-carboxylic } \\
\quad \text { acid (V) } \\
\text { p-Orcinol-carboxylic acid } \\
\text { (VI) } \\
\text { Rhizoninic acid (VII) } \\
\text { Haematommic acid (VIII) } \\
\text { Haematommic acid } \\
\text { monomethyl ether }{ }^{* *} \text { (IX) } \\
\text { Orcinol-dicarboxylic acid } \\
\text { monomethyl ether } * * \text { (X) }\end{array}$ & $\left|\begin{array}{c}\text { Bluish-violet } \\
\text { Yellowish- } \\
\text { green } \\
\text { Green (intense) } \\
\text { Bluish violet } \\
\text { (intense) }\end{array}\right|$ & 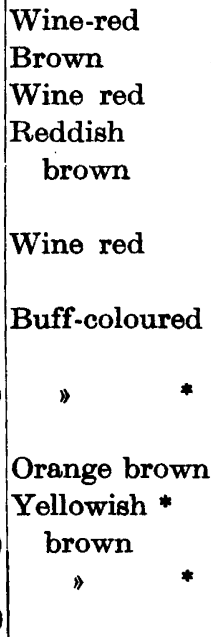 & $\begin{array}{l}+ \\
+ \\
-\end{array}$ & $\begin{array}{l}+ \\
-? \\
-\end{array}$ \\
\hline
\end{tabular}

* Distinct colours are obtained only on paper buffered to $\mathrm{pH}>8$.

* Not isolated in the pure state but obtained as hydrolysis products of depsides of known composition.

Table 2. Approximative $R_{F}$ values at $20^{\circ}$ on buffered paper.

\begin{tabular}{|c|c|c|c|c|c|c|c|}
\hline \multirow{3}{*}{ Substance } & \multicolumn{4}{|c|}{$n$-Butanol - water } & \multicolumn{3}{|c|}{$\begin{array}{c}n \text {-Butanol - benzene } \\
\text { water }(1: 1: 1)\end{array}$} \\
\hline & \multicolumn{4}{|c|}{$\mathrm{pH}$} & \multicolumn{3}{|c|}{$\mathrm{pH}$} \\
\hline & 4.5 & 6.8 & 9.0 & 11.7 & 6.8 & 9.0 & 11.7 \\
\hline Orsellinic acid (I) & 0.76 & 0.58 & 0.55 & 0.19 & 0.28 & 0.08 & 0.02 \\
\hline Everninic acid (II) & 0.90 & 0.78 & 0.74 & 0.73 & 0.57 & 0.30 & 0.27 \\
\hline Divaric acid (III) & 0.94 & 0.87 & 0.84 & 0.63 & 0.74 & 0.44 & 0.15 \\
\hline Divaricatinic acid (IV) & 0.95 & 0.94 & 0.93 & 0.92 & 0.87 & 0.75 & 0.74 \\
\hline Sphaerophorol-carboxylic acid (V) & 0.96 & - & 0.97 & 0.97 & 0.95 & 0.90 & 0.87 \\
\hline$\beta$-Orcinol-carboxylic acid (VI) & 0.91 & 0.68 & 0.60 & 0.39 & 0.46 & 0.16 & 0.05 \\
\hline Rhizoninic acid (VII) & 0.90 & 0.85 & 0.83 & 0.82 & 0.75 & 0.51 & 0.50 \\
\hline Haematommic acid (VIII) & 0.96 & 0.86 & 0.83 & 0.32 & 0.58 & 0.38 & 0.05 \\
\hline $\begin{array}{l}\text { Haematommic acid monomethyl } \\
\text { ether (IX) } \\
\text { Orcinol-dicarboxylic acid }\end{array}$ & - & 0.93 & - & 0.62 & - & - & - \\
\hline monomethyl ether (X) & 0.66 & 0.17 & 0.04 & 0.0 & 0.0 & 0.0 & 0.0 \\
\hline
\end{tabular}


moist atmosphere turns dark violet. With butanol - water as solvent the violet coloured substance divides into two spots with $R_{F} \sim 0$ and 0.04 respectively, and spraying with the benzidine reagent or examination in ultraviolet light reveals a third spot, deriving from the unchanged acid $\left(R_{F} \sim 0.39\right)$.

Table 2 shows some relationships between structure and $R_{F}$ values. As would be expected, the 2,4-dihydroxy acids and their 4-methyl ethers show increasing $R_{F}$ values with increasing number of methyl and methylene groups. Increasing $\mathrm{pH}$ decreases the $R_{F}$ values of the dihydroxy acids to a far greater extent than those of the methoxylated ones. Thus divaric acid (III) runs faster than everninic acid (II) at pH 9.0, whereas at $\mathrm{pH} 11.7$ the sequence is reversed.

At a low $\mathrm{pH}(<10)$ haematommic acid (VIII) runs much faster than the related $\beta$-orcinol-carboxylic acid (VI), and the strongly lipophilic character of the former must be due to intramolecular hydrogen bonding between the hydroxyl groups and the aldehyde group. When the $\mathrm{pH}$ is increased to 11.7, however, the $R_{F}$ values of the two acids lie close together. At this high pH the ionization of the hydroxyl groups is a factor of importance. The fact that the methyl ester of haematommic acid can be titrated with phenolphtalein as indicator shows that one phenolic hydroxyl group in the free acid is markedly acidic.

For comparison, the chromatographic behaviour of the analogous compounds atranol (XII) and $\beta$-orcinol (XI) was studied. As shown in Table 3, influence of hydrogen bonding is again evident.

Before the components of a depside can be investigated chromatographically, the depside must first be hydrolyzed and this step may present difficulties because of the ease with which some of the acids so formed, especially 2,4-dihydroxy acids, undergo decarboxylation even under the mildest conditions. However the resultant phenols can be readily distinguished from the phenolic acids, by virtue of their lack of fluorescence in ultra-violet light and their very high $R_{F}$ values in the solvent systems described. In $0.1 M$ trisodium phosphate solutions in the absence of air (to prevent oxidative degradation) lecanoric acid (XIII), evernic acid (XIV), divaricatic acid (XV) and sphaerophorin (XVI) are completely hydrolyzed in 1-2 days at room temperature and give the expected products, but the more resistant compounds squamatic acid (XVIII), baeomycessic acid (XVII) and atranorin (XIX) which belong to the $\beta$-orcinol group of depsides require $6-7$ days at room temperature or $1-2$ days at $40^{\circ}$. In the case of atranorin, subsequent chromatography revealed only one distinct fluorescent spot due to $\beta$-orcinol carboxylic acid (VI), and haematommic acid (VIII) was destroyed.

Cold concentrated sulphuric acid has been used to hydrolyse certain sterically hindered esters ${ }^{11,12}$ but does not appear to have been employed in the 
Table 3. $R_{F}$ values on buffered paper. Solvent system: benzene-water.

\begin{tabular}{|l|ccc|}
\hline & \multicolumn{3}{c|}{$\mathrm{pH}$} \\
\hline & 6.8 & 9.0 & 11.7 \\
\hline & & & \\
$\beta$-Orcinol (XI) & 0.25 & 0.25 & 0.25 \\
Atranol (XII) & 0.65 & 0.40 & 0.02 \\
\hline
\end{tabular}<smiles>[R20]C1CC([R12])C(C(=O)OC2CC([R16])C(C(=O)O)C(O)C2)C(O)C1</smiles><smiles>[R7]C1C(O)C[C@@H](C)C(C(=O)O[C@H]2C[C@H](C)[C@@H](C(=O)O)C(O)C2C)C1O</smiles><smiles>COC(=O)C1C(C)CC(OC(=O)C2C(C)CC(O)C(C=O)C2O)C(C)C1O</smiles>

XIII $\mathrm{R}_{1}=\mathrm{H}, \mathrm{R}_{2}=\mathrm{R}_{3}=\mathrm{CH}_{3}$

XIV $R_{1}=R_{2}=R_{3}=\mathrm{CH}_{3}$

$\mathrm{XV} \quad \mathrm{R}_{1}=\mathrm{CH}_{3}, \mathrm{R}_{2}=\mathrm{R}_{3}=n-\mathrm{C}_{3} \mathrm{H}_{7}$

XVI $\mathrm{R}_{1}=\mathrm{R}_{2}=\mathrm{CH}_{3}, \mathrm{R}_{3}=n-\mathrm{C}_{7} \mathrm{H}_{15}$

XVII $\quad \mathbf{R}=$ CHO

XVIII $R=\mathrm{COOH}$

XIX

case of depsides. Atranorin and squamatic acid have been succesfully hydrolyzed with this reagent, and although the hydrolysis is generally not complete the unchanged water-insoluble depside is easily removed and the expected products of hydrolysis have been identified.

Satisfactory hydrolysis may be obtained if the depside in acetone solution is applied to a paper strip buffered to a high $\mathrm{pH}$ and the paper is allowed to stand for at least 6-7 hours before irrigation with the solvent. Hydrolysis is seldom complete, but spots corresponding to the original depside and its fission products may be obtained in this way.

For the complete analysis of an unknown mixture of depside components it is usually necessary to run chromatograms with several different solvent systems and with papers buffered to different $\mathrm{pH}$ values. Final identification, of course, must always involve comparison with authentic reference substances. Even if unknown acids are encountered, considerations of the colours they produce with the various reagents together with their $R_{F}$ values often enable valuable deductions regarding their structures to be made. 
The methods described here may prove of value for the identification of the natural depsides as well as for the elucidation of their structures, and as is shown by the chromatograms obtained from $\beta$-orcinol (XI) and atranol (XII) (Table 3), the use of buffered paper is advantageous for the separation and identification of the phenols and hydroxyaldehydes which are often obtained as degradation products of lichen acids.

\section{EXPERIMENTAL}

Isolation of lichen acids

The following depsides have been isolated: Lecanoric acid (XIII) from Parmelia fuliginosa (Fr.) Nyl., Evernic acid (XIV) from Evernia prunastri (L.) Ach., Divaricatic acid (XV) from Haematomma ventosum (L.) Mass., Sphwerophorin (XVI) from Sphaerophorus fragilis (L.) Pers., Atranorin (XIX) from Stereocaulon-sp., Squamatic acid (XVIII) and Squamatic acid + Baeomycessic acid (XVII)-mixture from Thamnolia vermicularis f. taurica Shaer.

The isolation of the depsides was carried out mainly according to the methods referred to by Asahina 1. Purification was often facilitated by filtering the crude ether or acetone extracts through a short column of alumina. The purity of the depsides was established by melting point and eqvivalent weight determinations.

$$
\text { Preparation of depside components }
$$

The acids $I-V$ were obtained from the depsides by methanolysis and subsequent hydrolysis as described by Asahina 13 .

The methyl esters of $\beta$-orcinol-carboxylic acid (VI) and haematommic acid (VIII) were prepared from atranorin by the method of Robertson et al.14. Hydrolysis of the esters with concentrated sulphuric acid by Sonn's method ${ }^{12}$ yielded the free acids.

Rhizoninic acid (VII) was prepared from $\beta$-orcinol-carboxylic acid methyl ester by methylation with diazomethane and hydrolysis with sulphuric acid 12.

The acids I-VIII were all purified by treatment with alumina and recrystallisation. As these acids often melt with decomposition their purity was established by paper chromatography.

$\beta$-Orcinol (XI) and atranol (XII) were prepared from atranorin by the method of Pfau 15 and purified by vacuum sublimation.

$$
\text { Hydrolysis of depsides on a microscale }
$$

The depside or depside mixture $(2 \mathrm{mg}$ ) was dissolved in $0.1 \mathrm{M}$ trisodium phosphate $(1 \mathrm{ml})$ and the mixture was set aside in the absence of air. All the depsides which have been investigated were completely hydrolyzed after $6-8$ days at $20^{\circ}$ or $1-2$ days at $40^{\circ}$. The solutions were then acidified with $2 \mathrm{~N}$ sulphuric acid and extracted with ether $(0.3 \mathrm{ml})$.

Atranorin (XIX) $(20 \mathrm{mg}$ ) was dissolved in $100 \%$ sulphuric acid $(0.4 \mathrm{ml})$. After 10 minutes at room temperature the yellow solution was poured with stirring into ice-water 
$(30 \mathrm{ml})$. The resulting solution was filtered to remove a white, amorphous precipitate, the filtrate was extracted with ether $(2 \times 5 \mathrm{ml})$ and the ether solution was evaporated to a volume of $1 \mathrm{ml}$.

Squamatic acid (XVIII) was hydrolyzed in the same manner.

Paper chromatography

Filter paper (Whatman No. 1), cut into strips $54 \times 9 \mathrm{~cm}$, was soaked in buffer solution, pressed between sheets of thick filter paper to remove excess liquid and dried in the air. The buffers used were as follows: $0.1 M \mathrm{NaH}_{2} \mathrm{PO}_{4}$ (pH 4.5), $0.1 M \mathrm{NaH}_{2} \mathrm{PO}_{4}$ (1 volume), + $0.1 \mathrm{M} \mathrm{Na}_{2} \mathrm{HPO}_{4}$ (1 volume) ( $\mathrm{pH} \mathrm{6.8),} \mathrm{0.1} \mathrm{M} \mathrm{Na}_{2} \mathrm{HPO}_{4}$ (pH 9.0), $0.1 M \mathrm{Na}_{3} \mathrm{PO}_{4}$ (pH 11.7).

Freshly prepared acetone solutions of the pure acids, $1 \%$ with respect to each component, were used. The crude fission products of the depsides, obtained as described above, were used without further purification.

A thick sheet of filter paper, soaked with the solvent system used, was suspended in the tank to facilitate the vaporization of the solvents and the strips were generally allowed to remain in the tank for $6-7$ hours before irrigation with the solvent. This time was found to be sufficient to prevent trailing and to produce comparatively sharp spots, while oxidative destruction of the alkali-sensitive acids even on papers buffered to high $\mathrm{pH}$ was negligible. When the time was reduced to 2 hours, some trailing was noticed. The chromatograms were run for 7-8 hours in the case of butanol - water and about 3 hours in the case of butanol - benzene - water (1:1:1), the solvent advancing $27-30 \mathrm{~cm}$.

The air-dried chromatograms were examined in ultra-violet light, the positions of the spots being marked and the intensities of the fluorescence being noted. A small fluorescent band at the solvent front interferred with the detection of compounds having very high $R_{F}$ values, but in other cases spots containing $1 \mu \mathrm{g}$ of substance were easily detectable. The strips were then dipped in bisdiazotised benzidine solution ${ }^{10}$, set aside if necessary for 1-2 minutes to allow the coloured spots to appear, then washed with water and allowed to dry in the air. With papers buffered to high $\mathrm{pH}$ values the spots appeared immediately and the reaction is extremely sensitive, a distinct spot being obtained with, for example, $0.01 \mathrm{ml}$ of $0.01 \%$ orsellinic acid solution; at a $\mathrm{pH}$ of about 7 the spots may take some minutes to develop and the sensitivity is somewhat less. Some acids do not give any appreciable colouration under neutral or acidic conditions so that the paper may be sprayed with an alkaline buffer prior to treatment with the benzidine reagent.

Freshly prepared $0.5 \% p$-phenylene diamine in acetone solution is about as sensitive as the benzidine reagent, but the yellow spots formed are not stable, and after some days the paper becomes dark in colour. Ammoniacal silver nitrate solution was also used as a spraying reagent but appeared to be less sensitive than the other reagents.

Generally, the $R_{F}$ value of an acid was reproducible to within 5-10\%, when different strips were compared. On one single strip, however, the variation of the $R_{F}$ values was considerably less, not exceeding $2 \%$. 


\section{SUMMARY}

Methods are described for the separation and identification by paper chromatography of a number of phenolic acids, known to be components of depsides. The development of a method of hydrolysing certain depsides by means of concentrated sulphuric acid is recorded.

The author is indepted to fil. lic. T. E. Hasselrot, Naturhistoriska Riksmuseet, Stockholm, for the identification of some of the lichens and to AB Ferrosan, Malmö, for financial support.

\section{REFERENCES}

1. Asahina, Y. In Fortschritte der Chemie organischer Naturstoffe. 2 (1939). Wien.

2. Nolan, T.J. In Thorpe's Dictionary of Applied Chemistry. 7 (1946) 284.

3. Shibata, S. J. Pharm. Soc. Japan 64 (1944) 50; C. A. 45 (1951) 2929.

4. Asahina, Y. J. Japan. Botany $12-15$ (1936-1939).

5. Dahl, E. Meddelelser från Grönland $150: 2$ (1950).

6. Bray, H. G., Thorpe, W. V., and White, K. Biochem. J. 46 (1950) 271.

7. Goodall, R. R., and Levi, A. A. Nature 158 (1946) 675.

8. Goodall, R. R., and Levi, A. A. Analyst 72 (1946) 277.

9. Bate-Smith, E. C. In Partition Chromatography (Biochemical Society Symposia No. 3 ). (1949). Cambridge.

10. Koch, J. E., and Krieg, W. Chem. Ztg. 62 (1938) 140.

11. Newman, M. S. J. Am. Chem. Soc. 63 (1941) 2431.

12. Sonn, A. Ber. 62 (1929) 3012.

13. Asahina, Y. Ber. 68 (1935) 1130.

14. Curd, F. H., Robertson, A., and Stephenson, R. J. J. Chem. Soc. (1933) 130.

15. Pfau, A. S. Helv. Chim. Acta 9 (1926) 650. 